\title{
Salmonella Typhimurium: experiences from ReCENT EUROPEAN OUTBREAKS
}

\author{
Therese Westrell (therese.westrell@ecdc.europa.eu) ${ }^{1}$ \\ 1. European Centre for Disease Prevention and Control, Stockholm, Sweden
}

Salmonellosis is the second most common foodborne infection in the European Union (EU) with a notification rate of 34.6 cases per 100,000 population in 2006 [1]. The disease mainly causes gastrointestinal symptoms such as fever, diarrhoea, abdominal pain, nausea and vomiting but, depending on the strain and the vulnerability of the host, Salmonella infections can lead to septicaemia and sometimes death. Many efforts are therefore made to reduce the human burden of salmonellosis. As humans generally become infected by eating contaminated and insufficiently cooked food, the efforts are focused on EU-wide implementation of stricter control measures within the animal and food sectors. These have proven to be effective as the notification rates have been decreasing in the EU during the last years [1].

In this week's issue of Eurosurveillance, four European countries present recent outbreaks of Salmonella Typhimurium. $S$. Typhimurium is one of the two serotypes, the other being $S$. Enteritidis, accounting for the majority of salmonellosis cases in Europe (70-80\% of the cases with known serotypes) [1]. The emergence of multidrug-resistant $S$. Typhimurium strains, like the definite phage type (DT) 104, in several EU countries is worrying. It is though debatable whether infections with these strains result in higher hospitalisation rates and/or case-fatality rates than infections with other Salmonella strains. In this issue, Doorduyn et al. [2] describes an ongoing S. Typimurium DT104 outbreak in the Netherlands where more than $20 \%$ of the cases were hospitalised. Also $S$. Typhimurium strains fully susceptible to antibiotics can still cause widespread outbreaks. This is presented by Schmid et al. [3], Grandesso et al. [4] and Ethelberg et al. [5] in this issue.

These four papers highlight the importance of molecular subtyping in outbreak investigations, which permits to compare strains within and between countries. In the investigations presented, phage typing, Pulsed Field Gel Electrophoresis (PFGE) and Multiple Loci Variable Number of Tandem Repeats Analysis (MLVA) have been used in different combinations. The results show not only that links exist between the countries, as in the outbreaks described by Switzerland [3] and France [4] and some cases in Denmark, which all seem to be caused by the same strain, but that also several outbreaks of the same serotype but different strains may be ongoing in one country simultaneously $[2,3,5]$.

The impact of international food production and trade on infectious diseases is also worth mentioning in this respect. As shown by Schmid et al. [3] and Grandesso et al. [4] contaminated food products have the potential to cause widespread outbreaks in several countries. An even more illustrative example of that is the recent foodborne outbreak of Salmonella Agona linked to products intended primarily for consumption in the made-to-order sandwich trade. The outbreak resulted in over 160 salmonellosis cases in seven EU countries and had implications for additional European countries where the food product had been distributed $[6,7]$. In order to detect and minimise the extent of such international events, it is vital to ensure rapid communication between public health authorities in different countries and also with the food authorities. Within the human sector, the European Food- and Waterborne Diseases surveillance network (FWD), coordinated by the European Centre for Disease Prevention and Control (ECDC), has an important function as an informal network to assist in the detection of clusters or outbreaks with international dimensions. This network was used for information sharing in all four outbreaks described in this issue. Sometimes even a single case identified with the same strain in another country could be the key to finding the source, something which Doorduyn et al. [2] now will investigate in their case-control study.

Articles published in this issue also present a variety of innovative outbreak investigation methods. Doorduyn et al. [2] used food consumption studies differentiated by age groups to support the results of the case interviews in an outbreak primarily affecting children. Grandesso et al. [4] used case-case comparisons to identify the food items consumed by cases with a particular strain of $S$. Typhimurium compared to cases with other $S$. Typhimurium strains. Ethelberg et al. [5] used an even wider array of methods, including for example focus group interviews, matched case-control studies, cohort studies in point source sub-outbreaks, shopping list analyses, case-case interviews, extensive trace-back analysis including geographical analyses etc. Despite all these efforts, the sources of these outbreaks have not yet been identified although pork products are suspected in several of them. The Danish outbreak, which is still ongoing, is by now the largest salmonellosis outbreak recorded in Denmark since the present surveillance system was put in place in 1980 . This shows the difficulties that may be encountered in investigating foodborne outbreaks and pinpointing the source, even when the most advanced epidemiological techniques are being used. It is therefore relevant that Schmid et al. [3] bring the general issue of food safety legislation into this context and discuss potentials for improvement in this area based on current EU regulations. 


\section{References}

1. 1. European Food Safety Authority, European Centre for Disease Prevention and Control. The Community Summary Report on Trends and Sources of Zoonoses, Zoonotic Agents, Antimicrobial Resistance and Foodborne Outbreaks in the European Union in 2006, The EFSA Journal (2007), 130. Available from: http:// www.efsa.europa.eu/cs/BlobServer/DocumentSet/Zoon_report_2006_en,0. pdf?ssbinary=true

2. Doorduyn Y, Hofhuis A, de Jager CM, van der Zwaluw WK, Notermans DW, van Pelt W. Salmonella Typhimurium outbreaks in the Netherlands in 2008. Euro Surveill. 2008;13(44):pii=19026. Available from: http://www.eurosurveillance. org/ViewArticle. aspx?ArticleId=19026

3. Schmid H, Hächler H, Stephan R, Baumgartner A, Boubaker K. Outbreak of Salmonella enterica serovar Typhimurium in Switzerland, May - June 2008 , implications for production and control of meat preparations. Euro Surveill. 2008;13(44):pii=19020. Available from: http://www.eurosurveillance.org/ ViewArticle.aspx?ArticleId=19020

4. Grandesso F, Jourdan-da Silva N, Le Hello S, Roussel S, Rasson S, Rousseau C, Wyndels K, Robemanpianina I, Bourdeau I, Peyron C, Géhin RM, Moyano MB, Vogeleisen C. Excess of infections due to a multi-drug sensitive Salmonella enterica serotype Typhimurium in France in June 2008. Euro Surveill. 2008;13(44):pii=19022. Available from: http://www.eurosurveillance.org/ ViewArticle.aspx?ArticleId $=19022$

5. Ethelberg S, Wingstrand A, Jensen T, Sørensen G, Müller L, Lisby M, Nielsen EM, Mølbak K. Large outbreaks of Salmonella Typhimurium infection in Denmark in 2008. Euro Surveill. 2008:13(44):pii=19023. Available from: http://www. eurosurveillance.org/ViewArticle.aspx?ArticleId=19023

6. O'Flanagan D, Cormican M, McKeown P, Nicolay N, Cowden J, Mason B, Morgan D, Lane C, Irvine N, Browning L. A multi-country outbreak of Salmonella Agona, February - August 2008. Euro Surveill. 2008;13(33):pii=18956. Available from: http://www.eurosurveillance.org/ViewArticle. aspx?ArticleId=18956

7. European Centre for Disease Prevention and Control. Update on outbreak of Salmonella Agona in Ireland and other EU countries, 19 September 2008.Available from: http://ecdc.europa.eu/en/health_content/Articles/ article_20080918.aspx

This article was published on 30 0ctober 2008.

Citation style for this article: Westrell T. Salmonella Typhimurium: experiences from recent European outbreaks . Euro Surveill. 2008;13(44):pii=19019. Available online: http://www.eurosurveillance.org/ViewArticle. aspx?ArticleId=19019 